\title{
CUIDADO CLÍNICO E SOBREMEDICALIZAÇÃO NA ATENÇÃO PRIMÁRIA À SAÚDE
}

\author{
CLINICAL CARE AND OVERMEDICALIZATION IN PRIMARY HEALTH CARE
}

Charles Dalcanale Tesser (D) ${ }_{(0000-0003-0650-8289)^{1}}$

\footnotetext{
${ }^{1}$ Universidade Federal de Santa Catarina, Centro de Ciências da Saúde, Departamento de Saúde Pública, Florianópolis, Santa Catarina, Brasil.

$<$ charles.tesser@ufsc.br>
}

Resumo Este ensaio analisa a sobremedicalização (medicalização desnecessária e indesejável) gerada no cuidado médico aos adoecidos na atenção primária à saúde, discute como ocorre e como evitá-la. Articula na análise três grupos de concepções/saberes: concepções de doença (dinâmicas/ontológicas); concepções de causação (ascendente/multidirecional); eixos conceituais estruturantes do saber médico (anatomopatológico, fisiopatológico, semiológico, epidemiológico). A sobremedicalização deriva dos movimentos cognitivos dos profissionais na elaboração diagnóstica e terapêutica. Ela nasce da associação da concepção ontológica de doença com causação ascendente (fluxo causal que vai dos elementos materiais mais simples a dimensões e níveis mais complexos), em articulação com sobrevalorização do eixo anatomopatológico, geradora de excessivas intervenções diagnósticas e farmacoterapêuticas. Para evitar a sobremedicalização, propomos a associação virtuosa da concepção dinâmica de doença, com causação multidirecional e uso equilibrado dos eixos conceituais das doenças. Isso facilita: escuta qualificada; contextualização dos casos; mais criterioso uso de exames complementares; reconhecimento dos limites diagnósticos biomédicos; superação da razão metonímica (que despreza tudo o que não é saber cientificamente consagrado); amplificação da interpretação para além das 'doenças' e dos tratamentos para além dos fármacos/cirurgias, explorando os saberes dos usuários e profissionais, práticas complementares e a devolução de problemas para o manejo autônomo apoiado.

Palavras-chave medicalização; prevenção quaternária; atenção primária à saúde.
Abstract This essay analyzes the overmedicalization (unnecessary and unwanted medicalization) generated in the medical care to the ill in primary health care, and discusses how it happens and how to avoid it. The analysis combines three sets of conceptions/knowledge: conceptions of illness (dynamic/ ontological); conceptions of causation (ascending/ multidirectional); key conceptual and structuring ideas about medical knowledge (anatomopathological, physiopatological, semiological, epidemiological). Overmedicalization is due to the cognitive movements of the professionals in the development of diagnoses and therapies. It originates from the ontological conception of illness with ascending causation (causal flow that goes from the simplest material elements to more complex levels and dimensions), in combination with the overestimation of the anatomopathological key idea, which generates excessive diagnostic and pharmacotherapeutic interventions. In order to avoid overmedicalization, we propose the virtuous association of the dynamic conception of illness, with multidirectional causation and balanced used of the key conceptual ideas of the illnesses. This facilitates: a qualified listening; the contextualization of the cases; a more rigorous use of complementary exams; the recognition of the limits of the biomedical diagnoses; the overcoming of the metonymical reasoning (which disregards anything that is not scientifically-established knowledge); an expansion of the interpretation that goes beyond the 'illnesses' and treatments that go beyond drugs/surgeries, exploring the knowledge of the users and professionals and the return of the problems to autonomous supported management.

Keywords mmedicalization; quaternary prevention; primary heath care. 


\section{Introdução}

A medicalização social é um processo pelo qual problemas antes não médicos são definidos ou tratados como problemas médicos, usualmente em termos de doenças (Conrad, 1992). Trata-se de um processo social e cultural amplo e complexo, do qual participam vários agentes (van Dijk et al., 2016), que permeia a formação das subjetividades no mundo moderno (Rose, 2007). A medicalização transformou-se e intensificou-se no século XXI, difundindo-se na vida social e institucional, com a progressiva importância e desenvolvimento das biotecnologias, da individualização e tecnificação da avaliação e controle de doenças e riscos (Clarke et al., 2010).

Para Illich (1975), a medicalização social é essencialmente ruim, porque diminui a competência emocional, cognitiva e prática das pessoas e comunidades no manejo da maior parte das situações de dor, adoecimento, sofrimento e morte. Assim, ela faz decrescer a saúde, entendida como capacidade criativa de enfrentamento e normatividade ante as adversidades, oscilações e conflitos do meio e do sujeito (Canguilhem, 1978).

Conrad (2007) aborda a medicalização de forma mais descritiva e analítica, menos condenatória. Camargo Jr. (2013) lembra que ela por vezes foi benéfica, como no caso da Aids (e em desastres ambientais - vide Petryna, 2009), e que a medicalização pode ser desconstruída (caso da homossexualidade). Williams e Calnan (1996) apontaram que na modernidade tardia há maior reflexividade e crítica à medicalização.

Entretanto, é consensual que a medicalização, pelos profissionais de saúde, de muitos problemas/situações dos usuários na atenção primária à saúde (APS) é mais prejudicial que benéfica e deve ser evitada. Chamaremos doravante essa medicalização indesejável de sobremedicalização. Evitar a sobremedicalização realizada pelos profissionais e os danos iatrogênicos associados foi chamado na medicina de família e comunidade de 'prevenção quaternária' (P4) (Jamoulle, 2015a), o que é importante também devido ao alto potencial de danos das ações médicas (Makary e Daniel, 2016).

A P4 é um tipo de ação preventiva não dirigida a doenças, pessoas, sociedade ou meio ambiente, mas ao agir profissional clínico-sanitário (Tesser, 2017). Apesar de a P4 crescer lentamente em vários países (Jamoulle, 2015b), há poucos estudos desenvolvendo-a conceitualmente. Uma exceção foi um número especial da Revista Brasileira de Medicina de Família e Comunidade (RBMFC, 2015), com vários artigos sobre o tema.

Illich tinha uma crença paradoxal de que os médicos da APS podem contribuir para o saudável processo de desmedicalização, oferecendo "aos pacientes a oportunidade de desmedicalizar sua própria atitude em relação à dor, incapacidade, desconforto, envelhecimento, nascimento e morte" (Illich, 1982, p. 463); e assim “desenganchar [usuários] do sistema" (Illich, 1982, p. 470). 
Neste ensaio, apresentamos uma análise de como ocorre a sobremedicalização decorrente da ação médica no atendimento de usuários sintomáticos na APS. O objetivo é triplo: distinguir os processos em que se dá a sobremedicalização; compreender como ela ocorre; e indicar estratégias cognitivas e práticas para evitá-la (praticar P4).

Metodologicamente, ensaiamos uma articulação de conceitos e ideias dispersos na literatura médica e de saúde pública (relativas a concepções de doença/adoecimento, a seus fluxos causais e à estrutura do saber médico), segundo nossos objetivos. Trata-se de um ensaio teórico com um caráter aplicado, voltado à orientação da prática clínica na APS. Por isso, a discussão é focada na dimensão interacional da sobremedicalização, conforme Conrad (2007).

Inicialmente, destacamos os movimentos dos profissionais na interação clínica em que é produzida a sobremedicalização. A seguir, apresentamos uma grade conceitual interpretativa, cujas ideias-chave estão envolvidas na sobremedicalização, permitindo compreender, ao menos em parte, a geração dela e sua evitação. Finalmente, para fomentar essa evitação (P4), na medida em que a generalidade da nossa discussão permite e sem detalhar aspectos operacionais, vários deles trabalhados por Norman e Tesser (2015), derivamos diretrizes orientadoras para a ação profissional.

A sobremedicalização é também comum nas ações preventivas na APS (Tesser, 2017), mas não será abordada, devido às significativas diferenças entre a atenção aos sensivelmente adoecidos e a prevenção em assintomáticos (Tesser e Noman, 2016). Doutra parte, cabe ao leitor uma adaptação possível de nossas proposições para outras profissões e ambientes clínicos.

\section{Sobremedicalização e movimentos constituintes dos encontros clínicos}

Um encontro clínico ambulatorial, como uma consulta médica, pode ser descrito e analisado por meio de sua decomposição em seis movimentos interligados que ocorrem, grosso modo, sucessivamente: acolhida; escuta; investigação; elaboração da interpretação diagnóstica; socialização dessa interpretação; proposição, pactuação e execução do tratamento (Tesser e Luz, 2018). A interação clínica comporta também uma dimensão concreta e observável, visível: aquilo que profissional e usuário fazem; e pelo menos uma segunda dimensão invisível, cognitiva, que orienta o fazer profissional, na qual se articulam concepções de doença, de fluxo causal dos adoecimentos e saberes estruturantes da biomedicina. A Figura l esquematiza genericamente na sua metade superior o fluxo dos atos cognitivos dos médicos e na sua metade inferior as suas ações visíveis, com os movimentos aqui mencionados. 
Figura 1

Esquema de um encontro clínico (dimensões visível e invisível)

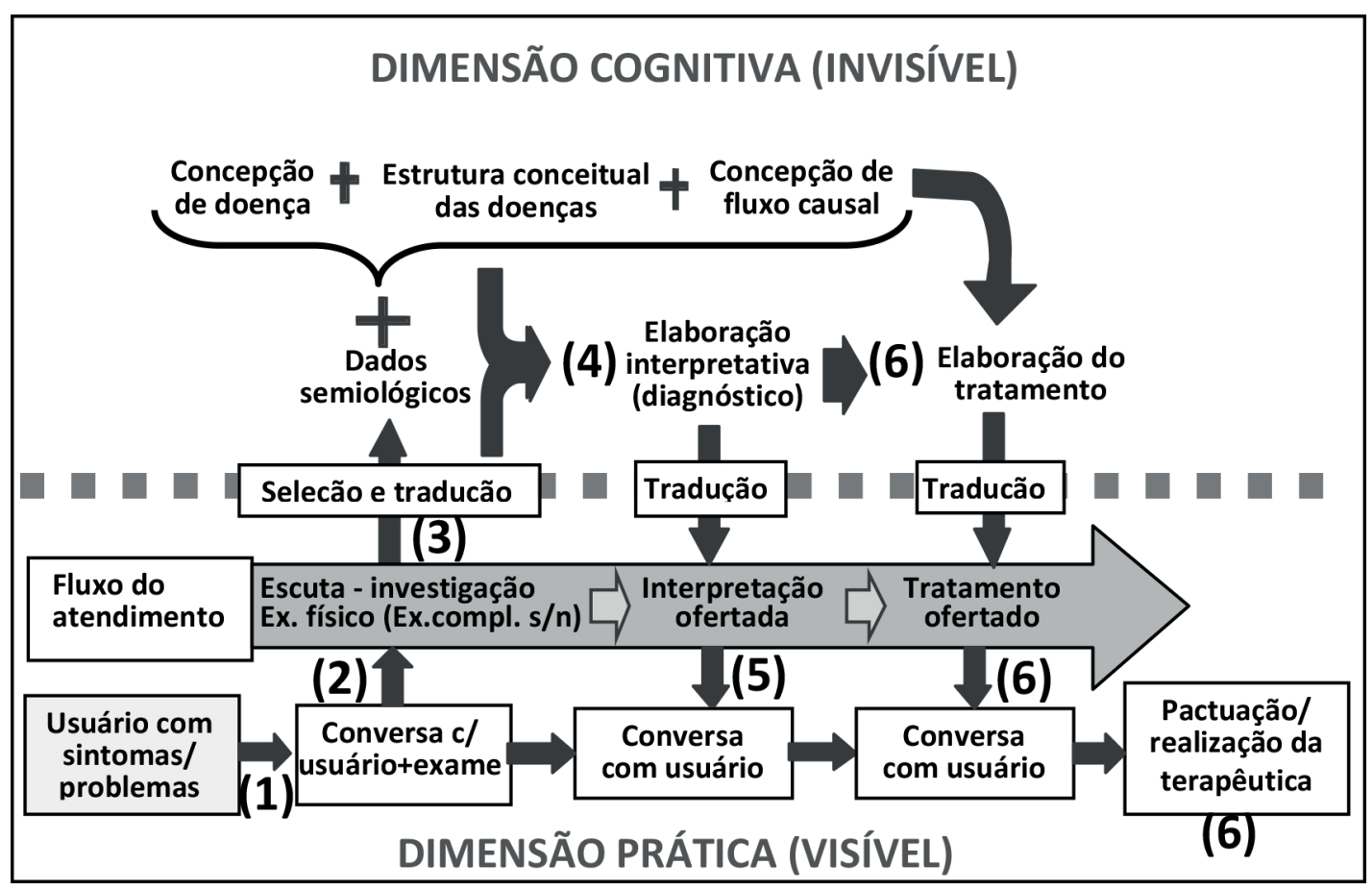

Legenda: (1)(2)...(6) = movimentos de um encontro clínico.

Fonte: O autor, com base em Tesser e Luz (2018).

Tal decomposição permite identificar, numa primeira análise, que a sobremedicalização proveniente da ação profissional ocorre originariamente nos movimentos cognitivos de elaboração das interpretações diagnósticas (movimento 4 da Figura 1), realizada ao longo dos movimentos 2 e 3, e de elaboração do tratamento (movimento 6 da Figura 1). O movimento 5 e a parte visível do 6 concretizam a oferta da interpretação e da terapêutica ao usuário, mas seu conteúdo e características nascem de sua contraparte cognitiva (invisível), aqui priorizada.

A elaboração do diagnóstico e sua socialização ressignificam a natureza do problema, independentemente de haver ou não sobremedicalização. Quando o problema é tipicamente aceito como merecedor de cuidado médico (considerado consensual e tecnicamente beneficiado por essa abordagem a tempo significativo, com mínimos ou aceitáveis prejuízos potenciais) não há medicalização nem sobremedicalização, mas interpretação e tratamento médicos cabíveis. Porém, quando esse não é o caso, a intepretação profissional pode concretizar a medicalização, a sobremedicalização ou a desmedicalização. A sobremedicalização pode não ocorrer ou ser desfeita, quando o profissional 
interpreta o problema como de natureza 'não médica' (ou 'não patológica') e ele é ressituado em outras esferas da vida do usuário e ali manejado (com apoio profissional).

A proposição/pactuação do tratamento, geralmente em coerência com o diagnóstico elaborado e socializado, reforça ou não a sobremedicalização. Ela é importante para a sobremedicalização também porque, além de reforçar os significados/sentidos da interpretação diagnóstica, tem sobre esta um efeito retroativo: como a interpretação é permeada por relevante pragmatismo, ela é balizada pelas possibilidades terapêuticas conhecidas e acessíveis, limitadas (Tesser e Luz, 2018).

Os movimentos 4 e 6 da Figura 1 são orientados por ideias e concepções disseminadas nos saberes, técnicas e práticas dos profissionais. Tais ideias/ concepções estão envolvidas na produção ou não da sobremedicalização e podem ser organizadas em três grupos: concepções gerais sobre a 'natureza' das doenças/adoecimentos; estrutura conceitual das doenças na biomedicina, que as caracteriza e explica uma a uma; fluxos causais envolvidos nos adoecimentos/doenças. Os dois primeiros grupos são mais ligados à elaboração das interpretações (movimento 4), enquanto o terceiro está também diretamente relacionado à elaboração/proposição da terapêutica (movimento 6). Com base na articulação de elementos desses grupos, esquematizamos uma matriz compreensiva da geração de sobremedicalização, orientadora de sua compreensão e minimização (Figura 2), a seguir abordada. 


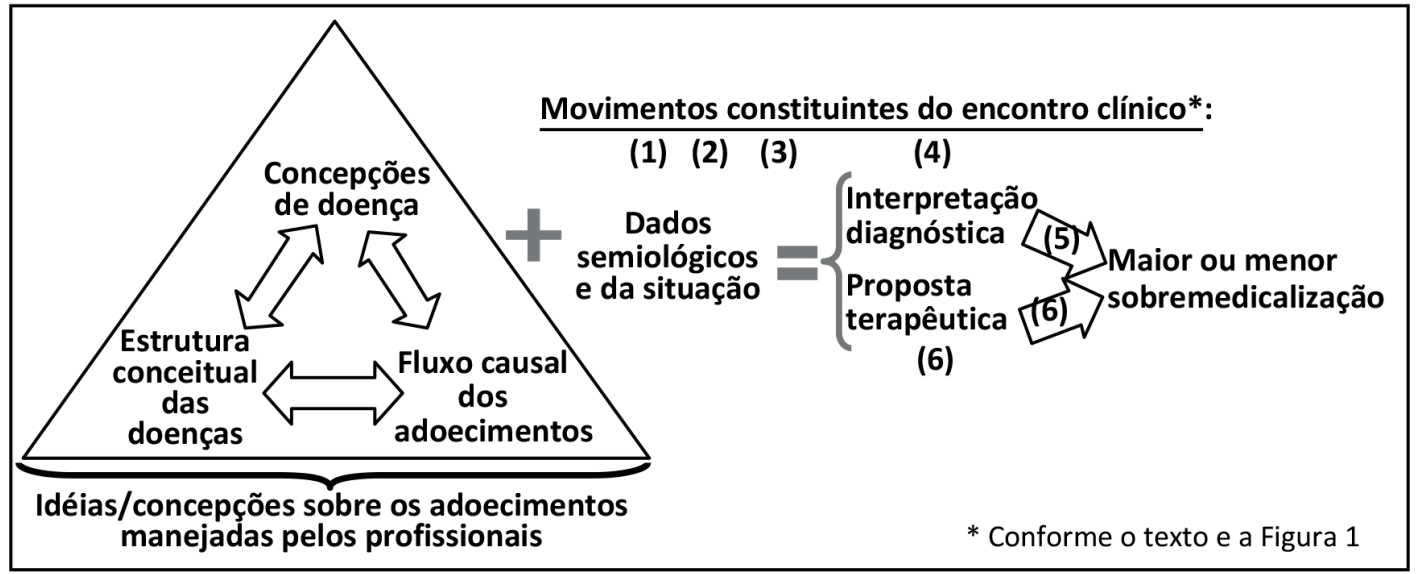

Fonte: $\mathrm{O}$ autor.

\section{Concepções de doença/adoecimento: ontológica e dinâmica}

Os profissionais usam concepções sobre a natureza das doenças que podem ser agrupadas em dois tipos polares: concepções ontológicas e dinâmicas. Nas concepções ontológicas, as doenças são vistas como se fossem seres ou coisas (já foram chamadas 'entidades mórbidas') (Albuquerque e Oliveira, 2002). Na biomedicina, seu aspecto identitário legitima sua abordagem via classificação científica, visando seu reconhecimento (diagnóstico), dandolhes status de fato objetivo (Camargo Jr., 2003; Almeida, 2002). Nessa concepção, as doenças seriam entidades independentes dos sujeitos e sua vida, existentes por si sós, descritas e classificadas pela nosografia biomédica. As pessoas adoecidas seriam 'portadoras' de doenças. Há um isolamento da doença em relação ao doente, que reforça a percepção de sua autossuficiência ontológica e epistemológica (objeto factual, delimitado e definido, estudável objetivamente pela ciência biomédica) (Tesser e Luz, 2002).

Embora concepções ontológicas sejam antigas e comuns em várias sociedades (Fleck, 2010), na biomedicina elas são hoje hegemônicas, tendo sido reforçadas pelas transformações que marcaram o nascimento e o desenvolvimento da clínica moderna. Na medicina classificatória dos séculos XVII e XVIII, as doenças eram classificadas em famílias, gêneros e espécies, como se fez com os seres vivos. Nessa classificação, estão pressupostas a independência e a autossuficiência ontológica das doenças. Cabia à ciência médica a função "de neutralizar os elementos acidentais representados pelo médico e o doente" (Yazbeck, 2012, p. 58). 
No século XVIII, uma mudança geral no saber médico faz nascer a medicina clínica: o olhar médico e sua linguagem tornam visíveis todas as doenças, agora fundadas no campo da percepção do médico, sobretudo no seu olhar: muda "a relação da doença com este olhar" (Yazbeck, 2012, p. 59). "Toda a mediação entre o olhar do médico e a essência da doença se dissolve" (Yazbeck, 2012, p. 59-60), propiciando a exaustiva visibilidade dela.

Outra mutação no início do século XIX atribuiu a essência das doenças às lesões dentro do corpo 'físico', com a realização sistemática da correlação anatomo(patologia)-clínica nos hospitais, localizando no interior do corpo doente a "doença em um órgão afetado, sua sede visível" (Foucault, 2008, p. 180). A anatomopatologia consolidou a concepção ontológica na biomedicina. No final do século XIX, a concepção ontológica foi reforçada ainda mais pela atribuição de causalidade aos germes, e a ambição classificatória persistiu na biomedicina do século XX (Illich, 1975), assim como a busca de objetivação visual das lesões/alterações patológicas corporais. Isso continuou com o desenvolvimento da genética (outra sede de causas) e com o desenvolvimento tecnológico da investigação do interior do corpo vivo. No século XXI, as doenças continuam sendo objetivadas em imagens e dosagens bioquímicas/biofísicas.

A grande valorização científica da objetivação das doenças no corpo obscurece o caráter grandemente construído, abstrato, artificial, modelístico e convencional delas, reforçando a disseminação das concepções ontológicas nas representações sociais e no ideário profissional.

Nas concepções dinâmicas de adoecimento, como o nome sugere, o adoecimento é entendido como um desequilíbrio entre forças que permeiam os humanos, a natureza e a sociedade, dentro e fora das pessoas. Há ênfase no aspecto processual e dinâmico, sendo o adoecimento visto como relativo à unidade do ser humano, cujas 'partes' e funções estão interligadas em processos complexos, sobre os quais múltiplas influências (internas e externas à pessoa) coexistem. Nessas concepções, a pessoa é vista como totalidade e unidade complexa cambiante, cujas várias dimensões, forças, aspectos e relações (biológicas, ambientais, psicológicas, espirituais e sociais) são interinfluenciáveis, embora com sintomas muitas vezes localizados (Myers e Benson, 1992; Albuquerque e Oliveira, 2002; Norman e Tesser, 2015).

É fácil perceber que as concepções dinâmicas estão associadas a uma abordagem clínica em que há maior abertura para os vários aspectos das vidas das pessoas e suas características psicossociais, suas vivências dos adoecimentos, universo que vai além da especificação dos sintomas das doenças (ou síndromes/transtornos) e suas alterações corporais/mentais, como classificadas biomedicamente. Elas pressupõem e mesmo facilitam um trabalho de construção de interpretação contextualizada da situação e vivência do usuário, em que o profissional tem um papel mais ativo do que a identificação da 
doença/síndrome/transtorno (quando possível) e a aplicação de terapêuticas padronizadas indicadas.

Esse maior protagonismo epistemológico não é demandado pelas características das concepções dinâmicas, embora elas o facilitem, mas principalmente pela comparação com as características do saber biomédico e suas técnicas correlatas. Estas, ao contrário, dificultam a produção de uma diagnose que integre também aspectos situacionais (sociais, familiares, laborais) e subjetivos (psicológicos e culturais) do adoecimento (Tesser, 2006, 2007). Na biomedicina, o uso desses aspectos tende a ocorrer posteriormente à elaboração interpretativa diagnóstica e terapêutica, na proposição do diagnóstico e pactuação do tratamento diante das condições sociais, valores e preferências dos usuários (movimentos 5 e parte prática do 6 da Figura 1). Além disso, esse uso apenas tardio, quando acontece, é comumente restrito devido à pouca variabilidade dos tratamentos, pensada mais como viabilização deles e produção de 'aderência'. Isso subvaloriza e desestimula o exercício de uma clínica que considere tais aspectos, chamada de ampliada por Campos (2003) e Cunha (2005).

Concepções dinâmicas também são usadas na biomedicina em algumas situações, mas de forma específica e restrita. Alguns avanços na biomedicina envolveram mudanças localizadas de uma concepção ontológica para dinâmica. Por exemplo, nas diarreias infantis agudas, a concepção anterior via o problema como infeccioso e o combatia com antibióticos e se necessário, para combater desidratação, com infusão intravenosa de fluidos, tentando tratar a causa e a consequência grave. Porém, uma abordagem dinâmica que gera suporte hídrico, salino e calórico para o organismo e a mucosa intestinal, independentemente dos germes (facilitando a autocura e evitando as complicações), após resistência acadêmica e testagem pragmática em campos de refugiados no terceiro mundo, revolucionou o tratamento (Fontaine e Newton, 2001). A terapia de reidratação oral foi considerada a mais importante descoberta médica do século XX (Lancet, 1978). Mesmo assim, o modo de manejo clínico costuma ser relativamente semelhante e padronizado: apenas os protocolos de diagnose e tratamento mudaram radicalmente, mas permaneceu a centralidade na doença, agora considerada como síndrome. Ou seja, mesmo quando presentes, concepções dinâmicas tendem a ser ofuscadas pelo destaque que as doenças e síndromes detêm na produção do saber e na prática clínica (Luz, 1988; Camargo Jr., 2003, 2005).

\section{Fluxos causais: causação ascendente e multidirecional}

Os profissionais usam concepções de fluxos causais envolvidos nos adoecimentos/doenças, operativos no saber médico e na sua prática clínica. 
Elas são importantes para a interpretação dos problemas e mais ainda para a ação terapêutica, facilitando ou não a sobremedicalização.

O debate filosófico ou epistemológico sobre causas não é necessário aqui e desviaria nossa discussão. Uma diferenciação básica é suficiente para nossos objetivos. Há uma concepção disseminada entre os profissionais, subjacente ao saber biomédico, de que os adoecimentos são causados por desvios da norma de variáveis ou estruturas biológicas (somáticas, materiais) objetiváveis ou mensuráveis (Engel, 1977; Borrell-Carrió, Suchman e Epstein, 2004). Nela está embutida uma noção de fluxo causal de natureza fisicalista, materialista e 'ascendente', derivada da física clássica (Camargo Jr., 2003).

O termo 'causação ascendente' se refere a fenômenos nos quais, em um sistema organizado, um nível mais básico produz eventos em um nível superior de organização (De Faria e Souza, 2014). Isso significa, na prática, um sentido de fluxo causal do micro para o macro e do simples para o complexo. Na área da saúde, as causas ou fluxos causais das doenças estariam em entidades ou níveis mais simples: germes, lesões ou problemas na maquinaria biomolecular do corpo. Assim, no processo de adoecimento, a causação iria das estruturas materiais mais elementares e simples (gens, moléculas, sistemas bioquímicos, células, tecidos, órgãos e sistemas do corpo e suas alterações anormais, incluindo seres invasores, germes e parasitas, e respectivas lesões 'patológicas') para os níveis mais complexos do ser e de sua existência (sintomas, sofrimentos, consciência, percepção, emoção, cognição etc.), progressivamente: do físicobioquímico para o perceptivo-corporal-mental-psicológico-espiritual.

De fato, há pouco espaço na estrutura conceital do saber biomédico para dimensões sociais, psicológicas e comportamentais das pessoas e seus adoecimentos. A doença costuma ser tratada como uma entidade independente do comportamento e da sociedade, dizia Engel (1977). Hoje, uma retificação mencionaria que o comportamento individual foi incluído, mais nas doenças crônicas.

No processo diagnóstico, o uso da causação ascendente induz e conduz, em coerência com a maioria das definições das doenças, a investigação (movimentos 2 e 3 da Figura 1) para o interior do corpo, afastando-a da complexidade ambiental, psicológica, familiar, social e laboral do usuário. Como consequência, produz uma pressão por objetivação visual da doença, fazendo o profissional tender para a solicitação excessiva de exames complementares e assim comumente desviar seu raciocínio clínico para direções pouco promissoras, com alto potencial de sobremedicalização, sobretudo na APS. Na elaboração da proposta terapêutica, a causação ascendente desvia o foco da intervenção para os germes ou mecanismos biomoleculares fisiopatogênicos ou semiogênicos.

A diagnose, assim dirigida, esclareceria a natureza (material-biológica) da doença (sediada no corpo), por meio de exames complementares ou critérios 
diagnósticos objetivos (quando não existem marcadores biológicos ou anatomopatológicos). Isso permitiria, via fluxos causais ascendentes, a terapêutica concebida como intervenção material no corpo, preparando o terreno onde opera o grosso da biomedicina: a farmacoterapia e as cirurgias, das quais se esperam cura/tratamento e prevenção das doenças (Camargo Jr., 2003; Almeida, 2002). Como se percebe, a causação ascendente tem estreita afinidade e coerência conceitual e operacional com a concepção ontológica de doença.

Engel (1977) já questionava esse reducionismo biológico, importante motor da sobremedicalização (Camargo Jr., 2010), e a adoção da causação unicamente ascendente. Para diminuir o reducionismo e desviar do dualismo mente-corpo nele implícito, apontou para a ideia de causação multidirecional. Nesta, níveis e dimensões mais amplas e complexas do ser humano (psicológico, social, cultural, ambiental) influenciam e interagem entre si e com níveis mais simples e materiais, de modo a configurar uma pluralidade direcional de fluxos causais, em que estão inseridas a causação ascendente e a descendente. A causação descendente ocorre quando um nível mais elevado ou complexo atua sobre um nível mais baixo da organização (Goswami, 2009; De Faria e Souza, 2014).

No fluxo causal multidirecional, os fenômenos da vida, os processos psicológicos e relacionais, a dinâmica cultural e cognitiva, os movimentos e conflitos afetivos e éticos dos usuários, bem como características dos seus ciclos e ritmos vitais (sono-vigília, trabalho-descanso/lazer, ciclo diário alimentar e qualidade da dieta), além de suas características econômicas e sociais, por vias pouco conhecidas mas já um tanto estudadas, interfeririam no processo saúde-doença, gerando adoecimentos. Admitida essa multidirecionalidade causal complexa, outros igualmente multidirecionais fluxos ou estímulos podem ser aceitos, coerentemente, como vias terapêuticas para reequilíbrio e cura. Na Figura 3, esquematizamos visualmente essas noções. A mudança da causação ascendente para a multidirecional é uma das chaves para evitar a sobremedicalização. 
Figura 3

Concepções de causação dos adoecimentos

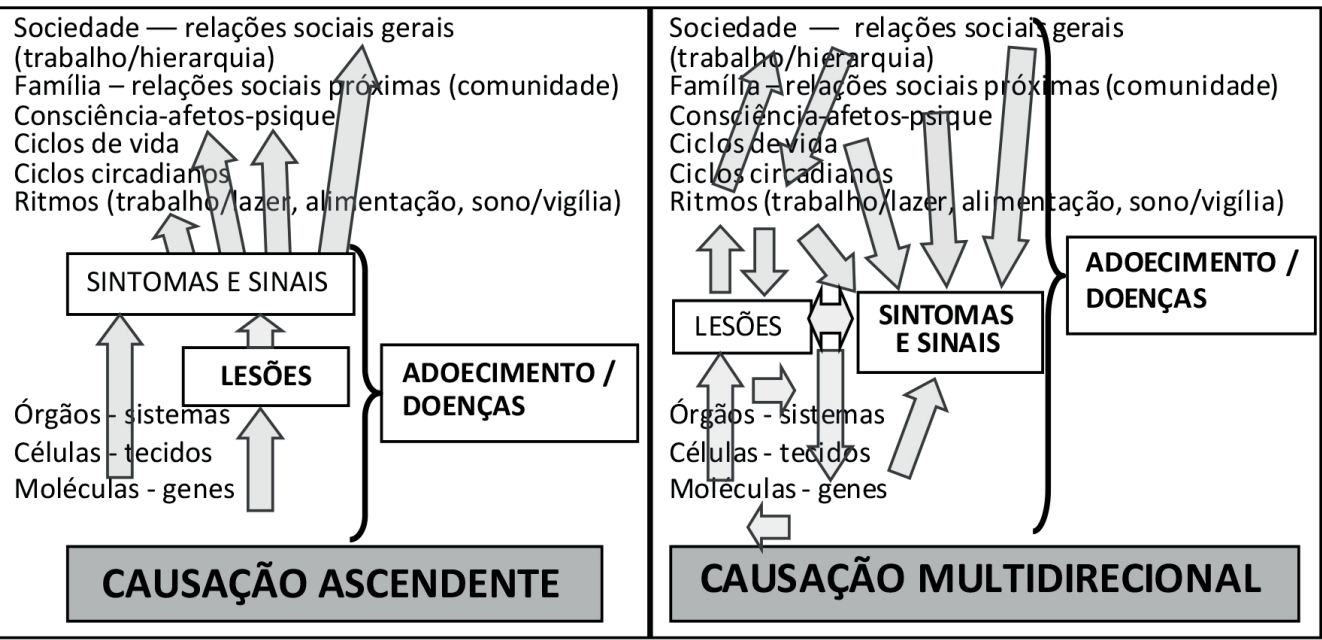

Fonte: O autor, baseado em Engel (1977) e Borrell-Carrió, Suchman e Epstein (2004).

\section{A estrutura conceitual das doenças}

Quatro eixos usados cotidianamente pelos profissionais organizam e constituem o grosso do saber biomédico sobre as doenças: o anatomopatológico, o fisiopatológico, o semiológico e o epidemiológico (Camargo Jr., 2003, 2005, 2010). O primeiro, nascido da anatomoclínica, é o mais antigo, mais valorizado e tem grande glamour tecnológico e científico, em razão do seu poder de objetivar alterações estruturais ou funcionais descritoras ou definidoras das doenças. Devido a sua grande legitimidade teórica, simbólica e operacional, o imaginário profissional a ele recorre tendencialmente, o que pressiona a ação na direção da objetivação da doença, geralmente via exames complementares, em coerência e sinergia com a concepção ontológica e a causação ascendente.

O eixo fisiopatológico oferece explicações e mecanismos para os adoecimentos (ou causas, quando conhecidas). Quadros como asma, alergias, refluxos gastroesofágicos, epilepsias e enxaquecas, por exemplo, costumam ser interpretados mais por meio desse eixo; e também doenças crônicas como diabetes, retocolites, doenças reumáticas, imunológicas, endócrinas etc. Ele também está comumente associado à concepção ontológica e à causação ascendente; e nessa associação tende a restringir a compreensão aos mecanismos fisiopatogênicos e semiogênicos ascendentes cientificamente conhecidos. Com isso, fornece modelos teóricos e explicações parciais fisiopatológicas que orientam farmacoterapias e cirurgias visando ao controle semio e fisiopatogênico. 
Geralmente, se há substrato anatomopatológico associado a uma doença, o eixo fisiopatológico fornece uma explicação das relações entre os componentes envolvidos, assim esses dois eixos caminham juntos. Todavia, quando não há tal substrato, frequentemente as interpretações diagnósticas centram-se no eixo fisiopatológico em si mesmo. Quando isso ocorre e persiste a sua associação à concepção ontológica e à causação ascendente, tende a haver um mimetismo reprodutor da abordagem centrada no eixo anatomopatológico: trata-se de tornar visível ou objetivar ao máximo o conjunto dos critérios diagnósticos, como níveis anormais de uma substância no sangue ou um conjunto de critérios diagnósticos com ou sem exames complementares. A doença passa a ser identificada por esses critérios, que 'substituem' então as lesões estruturais anatomopatológicas. Devido ao manejo diagnóstico similar, o eixo fisiopatológico pode ser considerado semelhante ao eixo anatomopatológico em sua contribuição para a interpretação diagnóstica, quando associado a uma concepção ontológica de doença e à causação ascendente. Nesse caso, também, sua influência sobre a cognição e a prática profissional tende a facilitar a sobremedicalização, na interpretação e na terapêutica.

O eixo semiológico, por sua vez, refere-se ao universo dos sintomas, sinais e queixas trazidos pelos usuários. Estes são hoje entendidos, geralmente, como a expressão clínica dos respectivos mecanismos anatomopatológicos e fisiopatológicos subjacentes (via causação ascendente). Paradoxalmente, esse é o eixo menos valorizado na ciência biomédica e o de mais alto valor clínico e social, pois é constituído da experiência vivida dos doentes, objetivo final da ação terapêutica (Camargo Jr., 1992). Outrora muito valorizado na medicina clássica, o eixo semiológico perdeu espaço em decorrência da geração de tecnologias - fármacos sintomáticos e exames complementares associados aos outros eixos - e da indução de seu uso por meio da cultura de consumo e de mercado das sociedades (capitalistas) em que se estruturou e desenvolveu a biomedicina. Todavia, na APS, muitos sintomas e queixas são pouco ou nada explicados biomedicamente e não diagnosticáveis via exames complementares (eixos fisiopatológico e anatomopatológico).

No manejo médico dos problemas cuja abordagem é centrada no eixo semiológico, no caso da impotência dos eixos anteriores, os sintomas em si mesmos tendem a ser tratados pelos profissionais como doenças, devido à força da concepção ontológica na cultura profissional. Mimetiza-se um diagnóstico de doença: o(s) sintoma(s) converte(m)-se em 'doença' via sinonímia técnica e transforma(m)-se na própria interpretação diagnóstica. Dor nas costas metamorfoseia-se em 'lombalgia', manejada como 'doença'. Dada a ampla disseminação da causação ascendente, por não haver potência explicativa fisiopatológica nem localização anatomopatológica, nesses casos os tratamentos restringem-se geralmente à supressão/redução dos sintomas, geralmente farmacoterapêutica. Ambas as tendências alimentam a sobremedicalização. 
Exemplos são abundantes: transtornos mentais, dores de cabeça inespecíficas, dores lombares inespecíficas, fibromialgias, dores articulares e periarticulares, dores abdominais e muitas outras manifestações, denominadas como sintomas físicos não explicáveis medicamente (MUPS - medically unexplained physical symptoms) (Jackson, George e Hinchey, 2009; Chitnis et al., 2011), os quais constituem de $15 \%$ a $30 \%$ das novas demandas trazidas à APS pelos usuários (JCP-MH, 2017). Estima-se que de $25 \%$ a $50 \%$ dos usuários da APS portem MUPS (Edwards et al., 2010).

O eixo epidemiológico refere-se ao adoecimento futuro e é centrado na categoria 'risco', operacionalizadora de várias práticas preventivas individuais, aqui não abordadas, também merecedoras de P4 (Tesser, 2017).

A relevância da articulação dessas concepções e saberes pode ser observada em um grave problema clínico e de saúde pública (Bulliard e Chiolero, 2015): o sobrediagnóstico nos rastreamentos de câncer. O sobrediagnóstico é o diagnóstico corretamente confirmado de uma patologia que permaneceria assintomática na vida da pessoa (Welch, Schwartz e Wolosin, 2011). Ele é derivado da associação do eixo anatomopatológico com a concepção ontológica de doença e a causação ascendente. Os rastreamentos de cânceres fundamentam-se na concepção ontológica associada à definição anatomopatológica da doença. Eles só são pensados e realizados porque se aceita: que há uma 'história natural da doença' (Leavell e Clark, 1976), como se ela tivesse uma vida própria independente que a faz evoluir sempre, se não houver intervenção; e que a doença é definida e identificada pela anatomopatologia: a alteração histológica é uma 'foto' da doença em evolução. Isso sustenta que alguém sentindo-se saudável, após rastreamento, receba tratamento precoce de um câncer assintomático. Ocorre que nos rastreamentos de vários cânceres produzem-se altas taxas de sobrediagnósticos (Singh et al., 2018), que por sua vez produzem sobretratamentos, porque indistinguíveis dos casos diagnosticados que adoeceriam, gerando o paradoxo da popularidade (Welch, Schwartz e Wolosin, 2011): os sobretratamentos são puro dano iatrogênico, mas todas as pessoas que os sofreram consideram-se salvas pelo rastreamento, popularizando-o. Esse exemplo é uma forte evidência da necessidade de se transformar a concepção ontológica para dinâmica e de reconhecer a não rara insuficiência e periculosidade da sobrevalorização do eixo anatomopatológico.

\section{O círculo vicioso da sobremedicalização}

Nas práticas clínicas na APS, costuma haver associação entre a concepção ontológica de doença, a causação ascendente e a sobrevalorização do eixo anatomopatológico (ou, na sua ausência, do fisiopatológico, manejado como o primeiro). Os eixos anatomopatológico e fisiopatológico podem ser, atual- 
mente, agrupados em um sentido comum de mensuração ou objetivação de estruturas ou variáveis biológicas (ou sintomas), usada para diagnóstico da doença ou transtorno. Em articulação com a causação ascendente, eles orientam, no tratamento, a interveção químico ou cirúrgica.

A aplicação generalizada dessas noções aos adoecimentos na APS leva, tendencialmente, a excessos de realização de exames complementares, com cascatas diagnósticas e alto potencial de danos iatrogênicos, além de desvios de raciocínio clínico, sobremedicalização de situações de vida cotidianas, medicalização de situações limítrofes e achados casuais como os incidentalomas (Mariño, 2015), também geradores de sobrediagnósticos. Configura-se, assim, um círculo vicioso de intervencionismo diagnóstico e terapêutico, com alto potencial de dano e sobremedicalização.

Como esses dois eixos das doenças (anatomopatológico e fisiopatológico) são a expressão maior da cientificidade biomédica, tal associação (concepção ontológica-causação ascendente-eixo anatomopatológico/fisiopatológico) é muito legítima e valorizada técnica e socialmente. Por isso, ela é sempre tendencialmente operada, mesmo em quadros clínicos em que não oferece êxito. Ela é também tendencialmente transladada para as miríades de situações em que apenas o eixo semiológico permite subsidiar a abordagem profissional, via conversão dos sintomas em sinonímia técnica mimetizando uma doença ou síndrome e reproduzindo o círculo vicioso sobremedicalizante (Figura 4). 


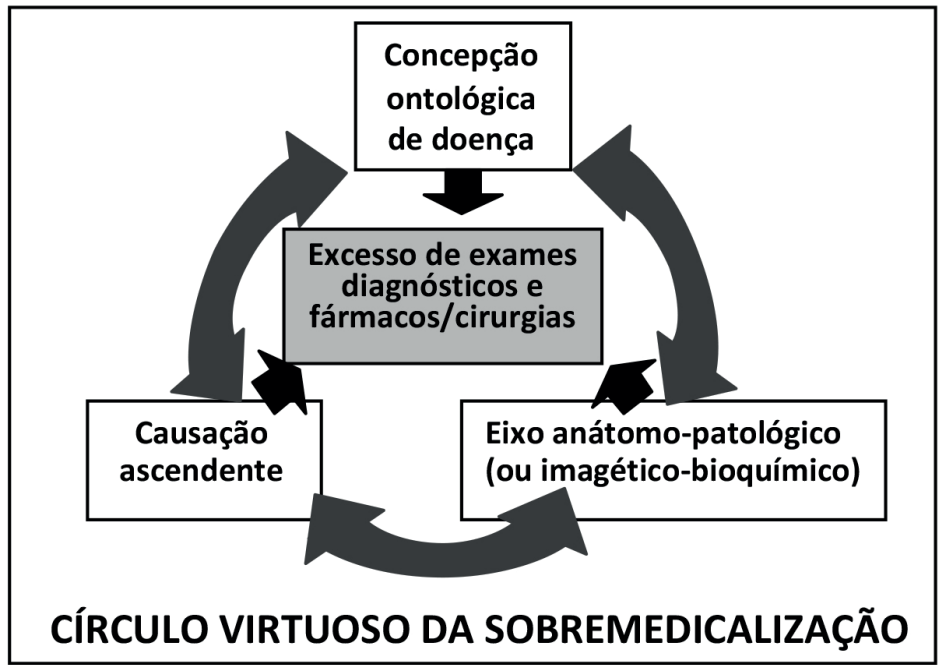

Fonte: $\mathrm{O}$ autor.

\section{O círculo virtuoso da proteção e da prevenção quaternária}

As afinidades e convergências entre as concepções dinâmicas e a causação multidirecional são evidentes, teoricamente e nos seus desdobramentos clínicos. Elas favorecem a consideração mais equilibrada e contextualizada dos eixos conceituais constitutivos das doenças nas interpretações diagnósticas e maior pluralidade e singularização nos tratamentos. Isso facilita que o enfoque propedêutico e terapêutico não deslize para a ênfase no eixo anatomopatológico (ou fisiopatológico) automaticamente em todas as situações, assim como não o subvalorize. Essa associação protege o usuário dos perigos do círculo vicioso da sobremedicalização e dirige a abordagem clínica em sentido virtuoso, de proteção do usuário e de P4.

Qualquer que seja o adoecimento, é desejável sua abordagem em uma concepção dinâmica com causação multidirecional, já que ambas são geralmente adequadas em quaisquer adoecimentos, particularmente naqueles em que os eixos fisiopatológico (sem o seu desvio mimetizador do anatomopatológico) ou semiológico (sobretudo este) são mais potentes para subsidiar a interpretação profissional (Norman e Tesser, 2015).

Há, entretanto, alguns problemas clínicos em que o uso restrito da causação ascendente, da concepção ontológica e do eixo anatomopatológico é satisfatório e justificável nos usuários sintomáticos. Isso ocorre em situações de maior gravidade, envolvendo a coletividade ou em que a intervenção terapêutica 
é poderosa ou iatrogênica (por exemplo: infartos do miocárido, meningites, tuberculose, cânceres etc.). Por isso, o uso cuidadoso da checagem de sinais de alarme na investigação é muito importante na APS. Nesses casos, em um segundo momento, esclarecida a situação e tomadas as medidas cabíveis, cabe retornar à abordagem dinâmica com causação multidirecional.

A associação virtuosa aqui mencionada é construtora de sentidos mais férteis para a participação do usuário no tratamento e no autocuidado. Como muitos problemas na APS são indiferenciados, de grande complexidade ou crônicos, a abordagem dinâmica em causação multidirecional assume maior importância, dada a sua abrangência no enfoque dos fatores intervenientes, incluídas aí as transformações no processo de vida dos usuários. Para evitar ou minimizar a sobremedicalização, há que praticar o círculo virtuoso mencionado, gerador de interpretações e tratamentos de modo seguro e protetor (Figura 5).

Figura 5

Círculo virtuoso da proteção e da prevenção quaternária

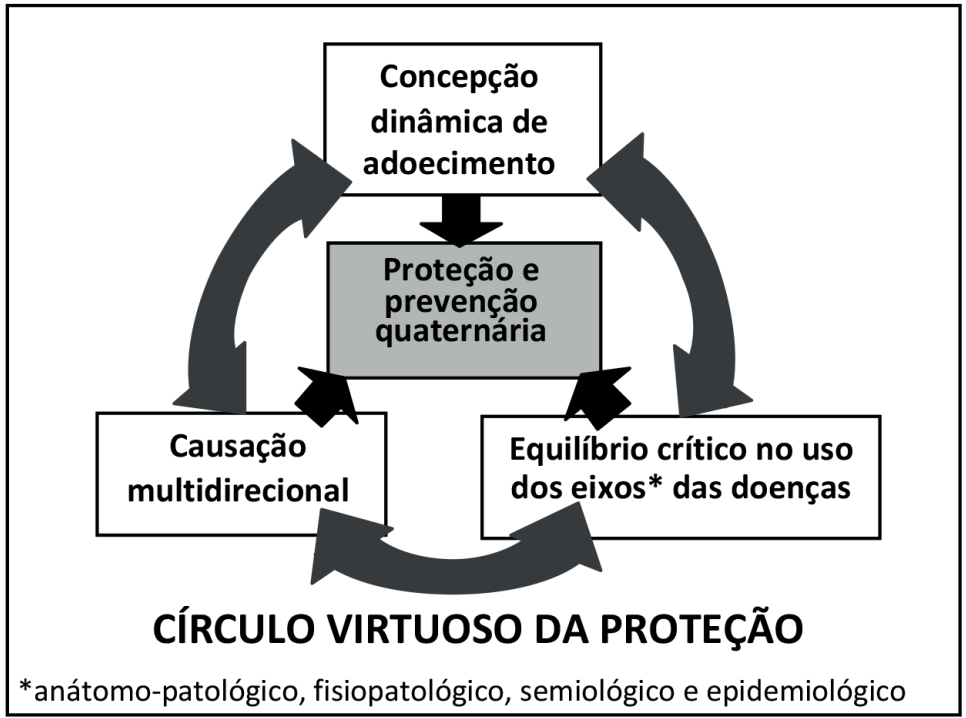

Legenda: *Eixos anatomopatológico, fisiopatológico, semiológico e epidemiológico.

Fonte: $\mathrm{O}$ autor.

A articulação entre concepções de doença e de seu fluxo causal com o manejo dos eixos conceituais (biomédicos) constitutivos das doenças na abordagem clínica, que oscila ora para o círculo vicioso da sobremedicalização, ora para o círculo virtuoso da proteção e P4, permite compreender - ao menos em parte e de modo útil ao manejo clínico - como ocorre a sobremedicalização na 
produção da interpretação diagnóstica e da proposta terapêutica (movimentos 4 e 6 da Figura 1). Agora, desdobremos da análise precedente orientações práticas para os movimentos concretos do encontro clínico.

\section{Escuta e investigação}

Os dados semiológicos mais importantes são obtidos na escuta; eles orientam a investigação e a interpretação diagnóstica (Tesser e Luz, 2018). A participação da escuta na sobremedicalização parece se dar mais pela sua interrupção, sua não realização plena ou seu direcionamento excessivo e precoce pelo profissional, que a converte em interrogatório na procura de uma patologia.

Como geralmente a escuta dirige a investigação, ambas viabilizam a elaboração da interpretação diagnóstica, podendo ser discutidas juntas. O círculo vicioso discutido aqui gera na escuta e na investigação a tendência automática, injustificável e perigosa de diagnose comprovada via exames complementares de forma generalizada e excessiva. Como já comentamos, isso induz sobremedicalização, iatrogenia e desvio prejudicial do raciocínio clínico.

Embora a maior parte da correção diagnóstica venha da escuta (complementada pelo exame físico), a pressão por objetivação da doença e a dificuldade de manejar as frequentíssimas situações na APS em que isso não é obtido tendem a pressionar os profissionais para a eliminação de doenças via exames complementares. No Brasil, a forte influência das especialidades médicas (que não medicina de família e comunidade) na formação médica faz com que essa preocupação de eliminar doenças, típica de tais especialidades (Birolini, 1998), seja comum e desemboque em uma avalanche sobremedicalizadora de solicitações mal fundamentadas desses exames. O uso criterioso e probabilístico de exames complementares, da demora permitida, da longitudinalidade, do acesso facilitado, da boa comunicação clínica sobre medos, preocupações e prognóstico mais provável, além de orientações em caso de sinais de alarme e agravações, é necessário para proteger a investigação da tendênca à sobremedicalização (Norman e Tesser, 2009). Afastada a concepção ontológica de doença, sem a obsessão de identificar doenças e tentando interpretar o adoecimento dinamicamente com atenção a sinais de alarme, a escuta e a investigação podem fluir sem tendência sobremedicalizante.

\section{Elaboração e socialização do diagnóstico}

O cuidado clínico na APS tem, dentre outras, duas faces: uma operacionalidade vivencial experimentada pelo doente e uma face técnico-epistemológica, 
vivenciada pelo profissional. Na primeira, os usuários buscam cura ou a melhoria para seus problemas sentidos. Na segunda face, como a construção do saber médico foi centrada nas doenças (Luz, 1988), a abordagem clínica dos profissionais dirige-se tendencialmente à sua identificação. Os problemas são então interpretados como doenças, cujos eixos conceituais são variáveis em robustez: oscilam de sintomas sem explicação, passam por síndromes e chegam até 'patologias' definidas, não ou mal explicadas, relativamente explicadas, com fisiopatologia parcialmente conhecida e anatomopatologia variável de ausente a bem estabelecida. As interpretações dos adoecimentos singulares são assim, progressivamente homogeneizadas e padronizadas (Camargo Jr., 2003; Dalmaso, 2000). A ética e a ação profissionais devem primar pela cura e cuidado dos usuários, mas seu saber é voltado para a cura e controle das doenças, cujo poder simbólico é muito grande e afeta a cultura geral e os doentes, além dos profissionais, ameaçando monopolizar a atenção.

O desencontro comum e por vezes dramático entre essas duas faces do cuidado profissional é reconhecido há décadas como problemático. Todavia, as iniciativas de reforma e melhoria da abordagem clínica na APS esbarram na imutabilidade do quase monopólio interpretativo das abstrações 'doenças' sobre a clínica da APS (Luz, 1988; McWhinney, 1978), ainda que, por vezes, acrescidas de 'problemas', quando os profissionais os registram e consideram nas interações. A necessidade de uma nova abordagem clínica centrada nos usuários a orientar o cuidado na APS é produto desse desencontro.

A abordagem clínica está cada vez mais dominada pelo seu polo científico (Dalmaso, 2000). O paradigma biomédico, no sentido kuhniano (Kuhn, 1987), apresenta muitas e importantes anomalias (McWhinney, 1984, 1993), a exemplo da subjetividade do doente (Guedes, Nogueira e Camargo Jr., 2009). Porém, mesmo em uma abordagem ampliada e abrangente que almeja centrarse nas pessoas e suas vivências, o principal processo cognitivo profissional no encontro é a elaboração da interpretação diagnóstica, que irá orientar a terapêutica. Nesse processo, atua a força (científica e sem concorrência) de enquadramento e redução do problema a uma ou mais 'doenças'. Essa força poderosa simplifica e homogeneíza o diagnóstico. Ela permite, nos ensaios clínicos, as comparações produtoras da eficácia 'comprovada cientificamente', em que operam os eixos constitutivos das doenças com forte tendência de se privilegiar o anatomopatológico (ou seu modo de manejo). A grande prevalência de situações não ou pouco enquadráveis, a grande limitação terapêutica nos quadros em que a fisiopatologia é pobremente explicativa (quase toda a biomedicina das doenças crônicas), a sua relativa monotonia terapêutica de redução de sintomas via fármacos e a sua iatrogenia comum tornam o encontro clínico não raramente angustiante para usuários e repetitivo para profissionais; cronificador, sobremedicalizante e frustrante para ambos. Reconhecer 
os limites diagnósticos e terapêuticos biomédicos é fundamental para a contenção do círculo vicioso sobremedicalizante na APS.

Um dos caminhos nessa direção é a reabilitação teórica e simbólica da capacidade interpretativa dos profissionais, hoje cada vez mais pobre e difícil de ser legitimada, para além da diagnose das doenças e síndromes, ou do uso da medicina baseada em evidências (que por seu turno também é homogeneizador). Nesse sentido, é preciso superar um aspecto da razão científica moderna que Santos (2002) chama de razão metonímica: sendo apenas um tipo de conhecimento poderoso em uma ecologia de saberes nas sociedades, essa razão (científica) imagina-se a única confiável e digna de crédito. A razão metonímica costuma ser mais drástica na cognição dos médicos, mas ela pode ser superada, para o que contribui um pragmatismo empírico e crítico (Almeida, 2002).

O duplo movimento de reconhecimento dos limites do saber biomédico e da superação da razão metonímica parece ser uma chave para evitar a sobremedicalização profissional, sobretudo nas abundantes situações em que não há 'doenças' nem sinais de alarme, ou as doenças e síndromes restringem-se ao eixo semiológico e fisiopatológico. Tal duplo movimento precisa se associar ao outro aqui discutido: a adoção da concepção dinâmica de doença, da causação multidirecional e de um consciencioso equilíbrio crítico entre os eixos conceituais das doenças na abordagem de cada situação, como uma associação virtuosa. Esse agora triplo movimento abre maior espaço para a construção da interpretação diagnóstica pelo profissional, com base em seus saberes (biomédicos ou não), a ser proposta ao usuário. A adoção de uma concepção dinâmica de adoecimento e da multidirecionalidade da causação facilita legitimar interpretações singularizadas e contextualizadas, em que os saberes biomédicos terão seu lugar conforme o caso.

O triplo movimento virtuoso aqui mencionado, revalorizador da interpretação do profissional em parceria com o usuário, ajuda a modular e orientar a interpretação diagnóstica nos encontros clínicos e evitar grande parte da sobremedicalização.

Muitas vezes, o simples contextualizar e legitimar sintomas (mentais e físicos) como reações adaptativas 'normais', recusando transformá-los em 'doenças', é um poderoso passo para evitar parte da sobremedicalização; exige habilidade comunicacional, boa escuta e cuidadosa avaliação clínica.

Outra possibilidade é a interpretação ser orientada por outros saberes especializados em saúde-doença não biomédicos, porventura acessíveis na APS. Na ecologia de saberes em saúde-doença, a biomedicina não é o único saber especializado e sofisticado; há outras racionalidades médicas (Luz e Barros, 2012) e práticas integrativas e complementares (PICs) que podem subsidiar interpretações (e tratamentos) na APS (Tesser, 2018). Enriquecer a interpretação diagnóstica é uma contribuição das PICs para evitar a sobreme- 
dicalização, se assim usadas, já que podem atuar também em sentido oposto (Mendonça e Camargo, 2012). A concepção dinâmica de doença de várias PICs e racionalidades médicas vitalistas (Greenwood, 1984) facilita a pluralização de terapêuticas em causalidade multidirecional e maior participação dos doentes nos seus cuidados (Andrade, 2006).

Por outro lado, os médicos recebem não raramente pressão dos doentes já medicalizados, que exigem exames e fármacos. Apesar da progressiva medicalização social, nem todos os usuários o fazem, e parcelas deles são dispostas a ressignificar seus adoecimentos (com ou sem diagnósticos de doenças). Os profissionais têm papel fundamental em ampliar esse espaço de ressignificação, cujo poder interpretativo e terapêutico pode surpreender e reduzir a sobremedicalização. De novo, o triplo movimento virtuoso mencionado facilita o reconhecimento da legitimidade de os profissionais exercitarem interpretações personalizadas contextualizadas e respectivos tratamentos.

Na prática, trata-se de desconstruir o automatismo protocolar diagnóstico e transitar o protagonismo interpretativo de uma suposta razão científica centrada em doenças ou evidências para os sujeitos em interação, reposicionando os saberes e técnicas ou tecnologias biomédicas, de modo a que sejam usados conforme a situação, assim como outros saberes pertinentes à interpretação, nas circunstâncias e valores de cada usuário.

\section{Terapêutica}

A realização do triplo movimento virtuoso mencionado facilita a compreensão de que os fármacos (e cirurgias) são apenas um tipo de tratamento possível, de tendência sobremedicalizante e a ser evitado quando possível e consensuado na interação. A associação entre a multidirecionalidade da causação e a concepção dinâmica de adoecimento e cura é a chave para a ressignificação das terapêuticas e sua pluralização de forma singularizada. Se isso é teoricamente pouco polêmico, pouco é desdobrado para a prática. A via farmacológica (em causação ascendente) de ação é uma herança biomédica legitimada científica e socialmente. Mesmo assim, e por isso mesmo, merece relativização forte, devido à sua grande sobremedicalização e iatrogenia, além da sua relativa inadequação tecnológica ante a diversidade dos problemas trazidos à APS. O envelhecimento populacional e a comum multimorbidade (Mangin e Heath, 2015) realçam os perigos do uso excessivo de fármacos no cuidado clínico.

A medicalização social gera insegurança e crenças imaginárias, que muitas vezes podem ser resolvidas com tranquilização, ressignificação das situações e formas criativas de enfrentamento. Grande parte de gripes e resfriados, dores, tristezas, ansiedades, insônias etc. melhoram com maior respeito aos processos adaptativos e promoção de autocura via cuidados domésticos e ou- 
tros, embora haja cada vez mais necessidade de ressignificação nesse sentido, devido à biomedicalização social.

O cuidado biomédico na APS já trabalha com uma noção de 'não intervenção' para parte dos problemas, por meio da demora permitida ou observação assistida (whatchfull waiting) (Norman e Tesser, 2009). A consideração dessa demora como 'não intervenção' está recheada de razão metonímica, como se exames complementares e fármacos fossem as únicas intervenções dignas de nota. A demora permitida não raramente gera um vazio terapêutico, um 'não fazer nada' frustrante. O triplo movimento virtuoso aqui mencionado facilita valorizar e propor terapêuticas não farmacológicas (incluindo ou não PICs) em interpretações singularizadas aos usuários.

A relativa pouca tradição com outras terapêuticas (não farmacológicas) na APS não significa que nelas não haja efetividade. O crescimento da pesquisa científica sobre PICs e sua persistente procura por populações e profissionais (WHO, 2013) sugere haver nelas mais potência interpretativa e terapêutica do que supõem os manuais médicos. Podemos evitar, nesse ponto, um 'fascismo tecnológico' (só os experts científicos decidem o que é eficaz e seguro) e um 'populismo tecnológico' (cientistas são desconsiderados) (Collins e Evans, 2007); e lembrar que há experts de distintas racionalidades médicas e PICs, os quais não merecem desprezo metonímico generalizado. Além disso, na APS, os profissionais já têm expertise biomédica e podem aprender outras racionalidades e PICs. Sua atuação na longitudinalidade com acesso facilitado funciona como mecanismo protetor dos usuários (Tesser, 2018), e nesse contexto institucional há uma grande proporção de situações em que a gravidade clínica é pequena, com os usuários pouco se beneficiando de fármacos e exames complementares. Por fim, vários desses problemas merecem cuidados (e se beneficiam deles) que vão além da demora permitida. Assim, a pluralização terapêutica (Tesser e Barros, 2008) e promocional na APS (Tesser, 2009) pode ser uma grande contribuição potencial das racionalidades médicas vitalistas e PICs à evitação da sobremedicalização.

A legitimação científica de tais práticas (PICs) pode ser maior, menor ou nula. Mesmo quando bem estudadas, podem não aparecer nos manuais biomédicos. Por exemplo, a meditação não está legitimada como tratamento da 'hipertensão arterial', mas já foi bem investigada e recomendada (Park e Han, 2017). A segurança das terapêuticas singularizadas e não convencionais é respaldada na competência técnica do profissional, no compromisso ético e na decisão compartilhada. Essa responsabilidade sempre está sobre os ombros profissionais: apenas estes sentem-se isentos delas e protegidos ao usar os fármacos (Tesser, 2007), já consagrados e de uso padronizado.

Devido ao menor poder simbólico na cultura geral, o profissional precisa primeiro ele mesmo valorizar interpretações singularizadas e respectivos tratamentos, para que possa realizá-los e injetar neles poder e legitimidade 
ao oferecê-los aos usuários. A compreensão e adoção do triplo movimento virtuoso mencionado é um auxílio teórico e simbólico nesse sentido. Tanto na elaboração interpretativa quanto na proposta terapêutica, há que se retomar o protagonismo do par profissional-usuário na construção dialogal da interpretação dos problemas e da pactuação terapêutica, para o que a comunicação empática horizontalizada é fundamental, conforme propostas de reforma ou ampliação da abordagem clínica (Cunha, 2005; Stewart et al., 1995).

\section{Considerações finais}

A comum associação de uma concepção ontológica de doença, da causação ascendente e da hipervalorização do eixo anatomopatológico (estruturante das doenças) na investigação, diagnose e terapêutica tende a gerar um círculo vicioso sobremedicalizante nas práticas profissionais na APS. Para evitar a sobremedicalização, recomendamos um triplo movimento virtuoso: articulação de uma concepção dinâmica de doença com causação multidirecional e equilibrado manejo dos eixos conceituais das doenças na abordagem dos problemas, com reconhecimento dos limites diagnósticoterapêuticos biomédicos e afastamento da razão metonímica. Esse triplo movimento facilita a melhoria da escuta; a evitação de cascatas diagnósticas desnecessárias; a ampliação das possibilidades interpretativas para além das 'doenças' (e sua ressignificação quando presentes); o uso mais criterioso de fármacos/cirurgias; e a revalorização/criação de terapêuticas contextualizadas singularizadas, de modo a explorar recursos diversos e PICs que façam sentido com base em situações existenciais e valores dos usuários, utilizando o tempo, o acesso fácil, a longitudinalidade, a hábil comunicação e os vários saberes dos usuários e profissionais.

\section{Financiamento}

Conselho Nacional de Desenvolvimento Científico e Tecnológico pelo financiamento parcial via bolsa de pós-doutorado (proc. 232320/2014-4) e bolsa de produtividade em pesquisa (proc. 303999/2018-7). 


\section{CUIDADO CLÍNICO Y SOBREMEDICALIZACIÓN EN \\ LA ATENCIÓN PRIMARIA DE LA SALUD}

Resumen Este ensayo analiza la sobremedicalización (medicalización innecesaria e indeseable) generada en el cuidado médico de los enfermos en la atención primaria de la salud, y discute cómo ocurre y cómo evitarla. El análisis articula tres grupos de concepciones/conocimientos: concepciones de enfermedad (dinámicas/ontológicas); concepciones de causación (ascendente/ multidireccional); ejes conceptuales estructurales del conocimiento médico (anatomopatológico, fisiopatológico, semiológico, epidemiológico). La sobremedicalización se deriva de los cambios cognitivos de los profesionales en la elaboración diagnóstica y terapéutica. Esta nace de la asociación de la concepción ontológica de enfermedad con causación ascendente (flujo causal que va desde los elementos materiales más simples a las dimensiones y niveles más complejos), en articulación con la sobrevaloración del eje anatomopatológico, provocadora de excesivas intervenciones diagnósticas y farmacoterapéuticas. Para evitar la sobremedicalización proponemos la asociación virtuosa de la concepción dinámica de enfermedad, con causación multidireccional y el uso equilibrado de los ejes conceptuales de las enfermedades. Esto facilita: escucha de calidad; contextualización de los casos; uso más riguroso de los exámenes complementarios; reconocimiento de los límites de los diagnósticos biomédicos; superación de la razón metonímica (que desprecia todo lo que no es conocimiento científicamente consagrado); ampliación de la interpretación más allá de las 'enfermedades' y de los tratamientos más allá de los fármacos/cirugías, aprovechando los conocimientos de los usuarios y profesionales, prácticas complementarias y la devolución de problemas para el manejo autónomo con apoyo.

Palabras clave medicalización; prevención cuaternaria; atención primaria de la salud. 


\section{Referências}

ALBUQUERQUE, Carlos M. S.; OLIVEIRA, Cristina P. F. Saúde e doença: significações e perspectivas em mudança. Millenium: Revista do ISPV, Viseu (Portugal), n. 25, jan. 2002 [Internet]. Disponível em:<http://www.ipv.pt/ millenium/Millenium25/25_27.htm >. Acesso em: 14 nov. 2018

ALMEIDA, Eduardo L. V. As razões da terapêutica: empirismo e racionalismo na medicina. Niterói: EdUFF, 2002.

ANDRADE, João T. Medicinas alternativas e complementares: experiência, corporeidade e transformação. Salvador: EdUFBA, EdUECE, 2006.

BIROLINI, Dario. A mão que controla a caneta. Medicina: Conselho Federal, Brasília, v. 12, n. 90, p. 24, 1998.

BORRELL-CARRIÓ, Francesc; SUCHMAN, Anthony L.; EPSTEIN, Ronald M. The biopsychosocial model 25 years later: principles, practice, and scientific inquiry. Annals of Family Medicine, Cleveland, v. 2, n. 6, p. 576-582, 2004.

BULLIARD, Jean-Luc; CHIOLERO, Arnaud. Screening and overdiagnosis: public health implications. Public Health Reviews, London, v. 36, n. 1, p. 1-5, 2015.

CAMARGO JR., Kenneth R. (Ir)racionalidade médica: os paradoxos da clínica. Physis: Revista de Saúde Coletiva, Rio de Janeiro, v. 2, n. 1, p. 203-230, 1992. <http://dx.doi.org/10.1590/ S0103-73311992000100008>.

CAMARGO JR., Kenneth R. Biomedicina, saber \& ciência: uma abordagem crítica. São Paulo: Hucitec, 2003.

CAMARGO JR., Kenneth R. A biomedicina. Physis: Revista de Saúde Coletiva, Rio de Janeiro, v. 15, supl., p. 177-201, 2005.

CAMARGO JR., Kenneth R. Medicalização: um quadro de referência. In: PINHEIRO, Roseni;
SILVA JR., Aluísio G. (orgs.). Por uma sociedade cuidadora. Rio de Janeiro: Cepesc, IMS/Uerj, Abrasco, 2010. p. 209-216.

CAMARGO JR., Kenneth R. Medicalização, farmacologização e imperialismo sanitário. Cadernos de Saúde Pública, Rio de Janeiro, v. 29, n. 5 , p. $844-846,2013$.

CAMPOS, Gastão W. S. Saúde Paidéia. São Paulo: Hucitec, 2003.

CANGUILHEM, Georges. O normal e o patológico. Rio de Janeiro: Forense Universitária, 1978.

CHITNIS, Anand et al. Guidance for health professionals on medically unexplained symptoms (MUS). London: The Forum for Mental Health in Primary Care, 2011.

CLARKE, Adele E. et al. Biomedicalization: technoscience, health, and illness in the U.S Durhan, NC: Duke University Press, 2010.

COLLINS, Harry; EVANS, Robert. Rethinking expertise. Chicago: University of Chicago Press, 2007.

CONRAD, Peter. Medicalization and social control. Annual Review of Sociology, Palo Alto, v. 18, p. 209-232, 1992.

CONRAD, Peter. The medicalization of society: on the transformation of human coditions into treatable disorders. Baltimore: The Johns Hopkins University Press, 2007.

CUNHA, Gustavo T. A construção da clínica ampliada na atenção básica. São Paulo: Hucitec, 2005.

DALMASO, Ana S. W. Análise de transformações da técnica em medicina: reflexões sobre uma proposta metodológica. Interface: Comunicação, Saúde e Educação, Botucatu, v. 4, n. 6, p. 49-60, 2000.

DE FARIA, Daniel L.; SOUZA, Helena S. Considerações sobre a causação descendente: um problema difícil. Clareira: Revista de Filosofia 
da Região Amazônica, Porto Velho, v. 1, n. 1, p. 31-54, 2014.

EDWARDS, Todd M. et al. The treatment of patients with medically unexplained symptoms in primary care: a review of the literature. Mental Health in Family Medicine, London, v. 7, n. 4, p. 209-221, 2010.

ENGEL, George L. The need for a new medical model: a challenge for biomedicine. Science, Washington, v. 196, n. 4.286, p. 129-136, 1977.

FLECK, Ludwik. Gênese e desenvolvimento de um fato cientifico. Belo Horizonte: Fabrefactum, 2010.

FONTAINE, Olivier; NEWTON, Charlotte. A revolution in the management of diarrhoea. Bulletin of the World Health Organization, Geneva, v. 79, n. 5, p. 471-472, 2001.

FOUCAULT, Michel. O nascimento da clínica. Rio de Janeiro: Forense Universitária, 2008.

GOSWAMI, Amit. Evolução criativa das espécies: uma resposta da nova ciência para as limitações da teoria de Darwin. São Paulo: Aleph, 2009.

GREENWOOD, Davydd J. Medicina intervencionista $v s$. medicina naturalista: história antropológica de una pugna ideológica. Arxiu d'Etnografia de Catalunya, Tarragona, v. 3, p. 59-81, 1984.

GUEDES, Carla R.; NOGUEIRA, Maria I.; CAMARGO JR., Kenneth R. Os sofredores de sintomas indefinidos: um desafio para a atenção médica? Physis: Revista de Saúde Coletiva, Rio de Janeiro, v. 19, n. 3, p. 797815, 2009.

ILLICH, Ivan. Nêmesis da medicina: a expropriação da saúde. São Paulo: Nova Fronteira, 1975.

ILLICH, Ivan. Medicalization and primary care. The Journal of the Royal College of General Practitioners, London, v. 32, n. 241, p. 463470, 1982.
JACKSON, Jeffrey L.; GEORGE, Susan; HINCHEY; Sherri. Medically unexplained physical symptoms. Journal of General Internal Medicine, Philadelphia, v. 24 , n. 4 , p. 540 542, 2009.

JAMOULLE, Marc. Quaternary prevention, an answer of family doctors to overmedic alization. International Journal of Health Policy and Management, Kerman (Iran), v. 4, n. 2, p. 61-64, 2015a.

JAMOULLE, Marc. Quaternary prevention: first, do not harm. Revista Brasileira de Medicina de Família e Comunidade, Rio de Janeiro, v. 10, n. 35, p. 1-3, 2015 b.

JOINT COMMISSIONING PANEL FOR MENTAL HEALTH (JCP-MH). Guidance for commissioners of services for people with medically unexplained symptoms. 2017. Disponível em: <https://www.jcpmh.info/wp-content/ uploads/jcpmh-mus-guide.pdf $>$. Acesso em: 14 nov. 2018

KUHN, Thomas S. A estrutura das revoluções científicas. São Paulo: Perspectiva, 1987.

LANCET (editorial). Water with sugar and salt. The Lancet, Oxford, v. 312, n. 8.084, p. 300-301, 1978. <http://dx.doi.org/10.1016/ s0140-6736(78)91698-7>.

LEAVELL, Hugh; CLARK, Edwin G. Medicina preventiva. São Paulo: McGrawHill do Brasil, 1976.

LUZ, Madel T. Natural, racional, social: razão médica e racionalidade científica moderna. Rio de Janeiro: Campus, 1988.

LUZ, Madel T.; BARROS, Nelson F. (orgs.). Racionalidades médicas e práticas integrativas em saúde: estudos teóricos e empíricos. Rio de Janeiro: Uerj/IMS/Lappis, 2012.

MAKARY, Martin A.; DANIEL, Michael. Medical error: the third leading cause of death in the US. BMJ, London, v. 353, p. i2139, 2016.

MANGIN, Dee; HEATH, Iona. Multimorbidity and quaternary prevention (P4). Revista 
Brasileira de Medicina de Família e Comunidade, Rio de Janeiro, v. 10, n. 35, p. 1-5, 2015. <http://dx.doi.org/10.5712/rbmfc10(35)1069>

MARIÑO, María A. Incidentalomas: concept, relevance and challenges for medical practice. Revista Brasileira de Medicina de Família e Comunidade, Rio de Janeiro, v. 10, n. 35, p. 1-9, 2015. <http://dx.doi.org/10.5712/ rbmfc10(35)1053>.

McWHINNEY, Ian R. Family medicine as a science. The Journal of Family Practice, New York, v. 7, n. 1, p. 53-58, 1978.

McWHINNEY, Ian R. Changing models: the impact of Kuhn's Theory on Medicine. Family Practice, Oxford, v. 1, n. 1, p. 3-8, 1984.

McWHINNEY, Ian R. Why we need a new clinical method. Scandinavian Journal of Primary Health Care, Stockholm, v. 11, n. 1, p. 3-7, 1993.

MENDONÇA, André L. O.; CAMARGO JR., Kenneth R. Complexo médico-industrial/ financeiro: os lados epistemológico e axiológico da balança. Physis: Revista de Saúde Coletiva, Rio de Janeiro, v. 22, n. 1, p. 215-238, 2012.

MYERS, Samuel; BENSON, Herbert. Psychological factors in healing: a new perspective on an old debate. Journal of Behavioral Medicine, New York, v. 18, p. 5-11, 1992.

NORMAN, Armando H.; TESSER, Charles D. Prevenção quaternária na atenção primária à saúde: uma necessidade do Sistema Único de Saúde. Cadernos de Saúde Pública, Rio de Janeiro, v. 25, n. 9, p. 2.012-2.020, 2009.

NORMAN, Armando H.; TESSER, Charles D. Prevenção quaternária: as bases para sua operacionalização na relação médico-paciente. Revista Brasileira de Medicina de Família e Comunidade, Rio de Janeiro, v. 10, n. 35, p. 1-10, 2015.

PARK, Seong-Hi; HAN, Kuem S. Blood pressure response to meditation and yoga: a systematic review and meta-analysis. Journal of Alternative and Complementary Medicine, New York, v. 23, n. 9, p. 685-695, 2017.

PETRYNA, Adriana. Biological citizenship after Chernobyl. In: HAHN, Robert A.; INBORN, Marcia (eds.). Anthropology and Public Health: bridging differences in culture and society. New York: Oxford University Press, 2009. p. 623-651.

REVISTA BRASILEIRA DE MEDICINA DE FAMÍLIA E COMUNIDADE (RBMF) [internet]. Rio de Janeiro, v. 10, n. 35, 2015. Disponível em: <https://www.rbmfc.org.br/rbmfc/issue/ view/44>. Acesso em: 14 nov. 2018.

ROSE, Nikolas. Beyond medicalisation. Lancet, Oxford, v. 369, p. 700-701, 2007.

SANTOS, Boaventura S. S. Para uma sociologia das ausências e uma sociologia das emergências. Revista Critica de Ciências Sociais, Coimbra, v. 63, p. 237-280, 2002.

SINGH, Harminder et al. Overdiagnosis: causes and consequences in primary health care. Canadian Family Physician: Le Médecin de Famille Canadien, Don Mills, v. 64, n. 9, p. 654-659, 2018.

STEWART, Moira et al. Patient-centered medicine: transforming the clinical method. Thousand Oaks, CA: Sage Publications, 1995.

TESSER, Charles D. Medicalização social (II): limites biomédicos e propostas para a clínica na atenção básica. Interface: Comunicação, Saúde e Educação, Botucatu, v. 10, n. 20, p. 347-362, 2006

TESSER, Charles D. A verdade na biomedicina, reações adversas e efeitos colaterais: uma reflexão introdutória. Physis: Revista de Saúde Coletiva, Rio de Janeiro, v. 17, n. 3, p. 465-484, 2007.

TESSER, Charles D. Práticas complementares, racionalidades médicas e promoção da saúde: contribuições pouco exploradas. Cadernos de Saúde Pública, Rio de Janeiro, v. 25, n. 8, p. 1.732-1.742, 2009. 
TESSER, Charles D. Por que é importante a prevenção quaternária na prevenção? Revista de Saúde Pública, São Paulo, v. 51, n. 116, p. 1-9, 2017. <http://dx.doi.org/10.11606/ s1518-8787.2017051000041>.

TESSER, Charles D. Práticas integrativas e complementares e racionalidades médicas no SUS e na atenção primária à saúde: possibilidades estratégicas de expansão. Journal of Management \& Primary Health Care, [internet], v. 8, n. 2, p. 216-232, 2018. Disponível em: <http:// www.jmphc.com.br/jmphc/article/view/528>. Acesso em: 14 nov. 2018.

TESSER, Charles D.; BARROS, Nelson F. Medicalização social e medicina alternativa e complementar: pluralização terapêutica do Sistema Único de Saúde. Revista de Saúde Pública, São Paulo, v. 42, n. 5, p. 914-920, 2008.

TESSER, Charles D.; LUZ, Madel T. Uma introdução às contribuições da epistemologia contemporânea para a medicina. Ciência \& Saúde Coletiva, Rio de Janeiro, v. 7, n. 2, p. 363-372, 2002. http://dx.doi.org/10.1590/ S1413-81232002000200015.

TESSER, Charles D.; LUZ, Madel T. Uma categorização analítica para estudo e comparação de práticas clínicas em distintas racionalidades médicas. Physis: Revista de Saúde Coletiva, Rio de Janeiro, v. 28, n. 1, p. e280109, 2018.

TESSER, Charles D.; NORMAN, Armando H. Differentiating clinical care from disease prevention: a prerequisite for practicing quaternary prevention. Cadernos de Saúde Pública, Rio de Janeiro, v. 32, n. 10, p. e00012316, 2016.

VAN DIJK, Wieteke et al. Medicalisation and overdiagnosis: what society does to medicine. International Journal of Health Policy and Management, Kerman (Iran), v. 5, n. 11, p. 619-622, 2016.

WELCH, H. Gilbert; SCHWARTZ, Lisa; WOLOSIN, Steven. Overdiagnosed: making people sick in the pursuit of health. Boston: Beacon Press, 2011.

WILLIAMS, Simon J.; CALNAN, Michael. The 'limits' of medicalization? Modern medicine and the lay populace in 'late' modernity. Social Science and Medicine, Oxford, v. 42, n. 12, p. 1.609-1.620, 1996.

WORLD HEALTH ORGANIZATION (WHO). WHO traditional medicine strategy: 2014-2023. Geneva: World Health Organization, 2013.

YAZBECK, André C. 10 lições sobre Foucault. 2. ed. Petrópolis: Vozes, 2012. 